\title{
LETTER
}

\section{Herbivore metabolism and stoichiometry each constrain herbivory at different organizational scales across ecosystems}

\begin{abstract}
Helmut Hillebrand, ${ }^{1 *}$ Elizabeth T. Borer, ${ }^{2}$ Matthew E. S. Bracken, ${ }^{3}$ Bradley J. Cardinale, ${ }^{4}$ Just Cebrian, ${ }^{5,6}$ Elsa E. Cleland, ${ }^{7}$ James J. Elser, ${ }^{8}$ Daniel S. Gruner, ${ }^{9}$ W. Stanley Harpole, ${ }^{10}$ Jacqueline T. Ngai, ${ }^{11}$ Stuart Sandin, ${ }^{12}$ Eric W. Seabloom, ${ }^{2}$ Jonathan B. Shurin, ${ }^{11}$ Jennifer E. Smith ${ }^{12}$ and Melinda D. Smith ${ }^{13}$
\end{abstract}

\section{Abstract}

Plant-herbivore interactions mediate the trophic structure of ecosystems. We use a comprehensive data set extracted from the literature to test the relative explanatory power of two contrasting bodies of ecological theory, the metabolic theory of ecology (MTE) and ecological stoichiometry (ES), for per-capita and population-level rates of herbivory across ecosystems. We found that ambient temperature and herbivore body size (MTE) as well as stoichiometric mismatch (ES) both constrained herbivory, but at different scales of biological organization. Herbivore body size, which varied over 11 orders of magnitude, was the primary factor explaining variation in per-capita rates of herbivory. Stoichiometric mismatch explained more variation in population-level herbivory rates and also in per-capita rates when we examined data from within functionally similar trophic groups (e.g. zooplankton). Thus, predictions from metabolic and stoichiometric theories offer complementary explanations for patterns of herbivory that operate at different scales of biological organization.

\section{Keywords}

Body size, ecological stoichiometry, grazing, herbivory, meta-analysis, metabolic theory of ecology, nutrient ratios, temperature.

Ecology Letters (2009) 12: 516-527

\section{INTRODUCTION}

The autotroph-herbivore interface is a major determinant of ecological function in a variety of earth's ecosystems. For example, cascading trophic interactions are often interrupted or mediated at the autotroph - herbivore level (McQueen et al. 1989; Brett \& Goldberg 1996; Borer et al. 2006) and the proportion of plant material passing through

\footnotetext{
${ }^{1}$ Institute for Chemistry and Biology of the Marine Environment, Carl-von-Ossietzky-University Oldenburg, Schleusenstrasse 1, D-26385 Wilhelmshaven, Germany ${ }^{2}$ Department of Zoology, Cordley Hall 3029, Oregon State University, Corvallis, 97331-2914 OR, USA

${ }^{3}$ Marine Science Center, Northeastern University, 430 Nahant Road, Nahant, 01908 MA, USA

${ }^{4}$ Department of Ecology, Evolution \& Marine Biology, University of California-Santa Barbara, Santa Barbara, 93106 CA, USA ${ }^{5}$ Dauphin Island Sea Lab, 101 Bienville Blvd., Dauphin Island, 36528 AL, USA

${ }^{6}$ Department of Marine Sciences, University of South Alabama, Mobile, 36688 AL, USA

${ }^{7}$ Department of Ecology, Behavior and Evolution, University of California, San Diego, 9500 Gilman Drive, La Jolla, 92036-0116 CA, USA
}

\footnotetext{
${ }^{8}$ School of Life Sciences, Arizona State University, Tempe, 852874501 AZ, USA

${ }^{9}$ Department of Entomology, 4112 Plant Sciences Bldg, University of Maryland, College Park, 20742 MD, USA

${ }^{10}$ Department of Ecology, Evolution and Organismal Biology, lowa State University, Ames, 50011 IA, USA

${ }^{11}$ Department of Zoology, University of British Columbia, 6270 University Boulevard, Vancouver, V6T 1 Z4 BC, Canada

${ }^{12}$ Center for Marine Biodiversity and Conservation, Scripps Institution of Oceanography, University of California, San Diego, La Jolla, 92093-0202 CA, USA

${ }^{13}$ Yale University, Department of Ecology and Evolutionary

Biology, PO Box 208106, New Haven, 06520-8106 CT, USA

*Correspondence: E-mail: hillebrand@icbm.de
} 
herbivores (as compared to detritus) regulates the fate of $\mathrm{C}$ as well as nutrient cycling in ecosystems (McNaughton et al. 1988; Cebrian 1999; Cebrian \& Lartigue 2004; Shurin et al. 2006). Thus, identifying the constraints on herbivory across ecosystems is an important task in ecology (Gruner et al. 2008; Schmitz 2008). In recent years, two distinct bodies of theory - the metabolic theory of ecology (hereafter MTE) and the theory of ecological stoichiometry (hereafter ES) have emerged, which may explain large-scale variation in trophic interactions.

Metabolic theory of ecology (Brown et al. 2004) posits that consumer body mass and body temperature together predict per-capita rates of metabolism, respiration, growth, and consumption and that these rates can be scaled up to the levels of populations and communities. A major appeal of MTE lies in its integrated approach, which uses first order physical principles to extrapolate from basal metabolic rates of individuals to higher levels of biological organization (Ernest et al. 2003; Woodward et al. 2005). These principles result in allometric scaling relationships between the main variables that comprise the MTE (body mass and body temperature) and physiological and ecological processes on cellular, organism and ecological levels. MTE is mechanistically based on distribution networks (West et al. 1997). For our study, we do not cover these mechanisms, but address the explanatory power of the main constituents (temperature and size) for herbivory. While body size and temperature generally are identified as important determinants of predator-prey interactions (Yodzis \& Innes 1992; Emmerson \& Raffaelli 2004; Shurin \& Seabloom 2005;
Brose et al. 2006), their importance for herbivory has never been explicitly tested across ecosystem types.

Allometric scaling relationships based on MTE predict increased per-capita rates of herbivory with increasing herbivore body size (Fig. 1a). Less obvious are the predictions for population-level rates of herbivory. One might expect independence of body size and populationlevel herbivory (Fig. 1d) if - as predicted by the energyequivalence rule (Damuth 1981) - population size decreases with increasing body size proportional to the increasing percapita consumption rate (Damuth 1981; Nee et al. 1991; Damuth 2007; White et al. 2007). However, if energyequivalence does not apply (Loeuille \& Loreau 2006), other (positive or negative) relationships might emerge depending on the existence of size-dependent differences in the costs of consumption. For example, Economo et al. (2005) found that assimilation per unit biomass decreases with increasing biomass in vertebrates. If this relationship is linked also to ingestion rates, many small consumers might ingest more than few large ones, decreasing population herbivory rates with increasing body mass.

The second focus of MTE is body temperature, but these data are rarely available from herbivory studies. However, the scaling of consumer resource dynamics strongly depends on the deviation between the ambient temperature and the thermobiology of the consumer (Yodzis \& Innes 1992; Vasseur \& McCann 2005). Hence, scaling relationships with ambient temperature can be formulated based on organisms' thermobiology (c.f. Allen et al. 2002; Meehan et al. 2004), leading to different expectations for endo- and ectothermic

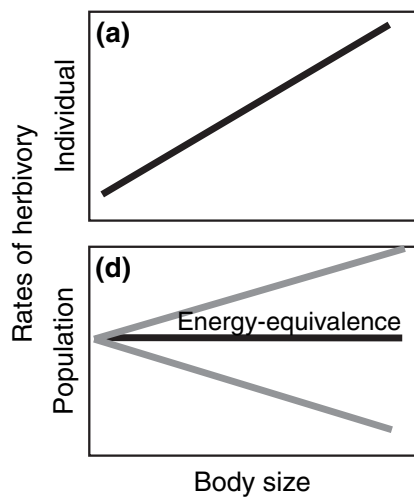

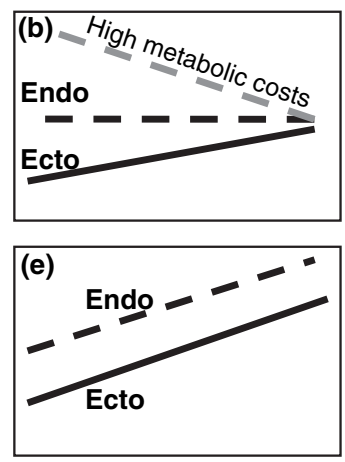

Ambient temperature
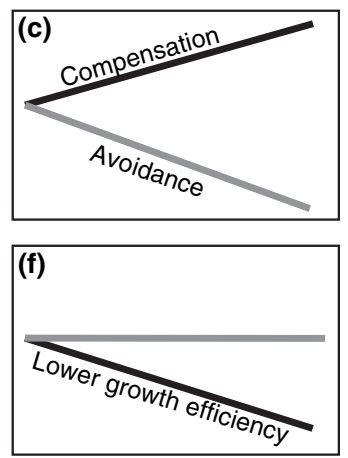

Stoichiometric mismatch

Figure 1 Expected patterns of metabolic (a-b, d-e) and stoichiometric (c, f) constraints on herbivory at individual and population-levels. (a) per-capita (individual) rates of herbivory are expected to increase with body size. (b) per-capita rates of herbivory increase with ambient temperature for ectotherms (solid line). Endothermic individuals (dotted lines) are predicted to decrease consumption rates if high metabolic costs are connected to maintenance of endothermy at low ambient temperature. (c) per-capita rates of herbivory increase with increasing stoichiometric mismatch if individuals perform compensatory feeding, but decrease if they avoid poor quality food. (d) population rates of herbivory are independent of herbivore body size only if the energy-equivalence rule applies. (e) population rates of herbivory increase with increasing ambient temperature for both endothermic and ectothermic herbivores. (f) population rates of herbivory decrease with increasing stoichiometric mismatch if the latter reduces population growth efficiency. 
herbivores. For ectotherms, ambient and body temperature are broadly correlated despite the fact that some organisms use behavioural or physiological mechanisms to maintain body temperature above ambient temperature (Bishop \& Armbruster 1999; Bryant et al. 2002). Therefore, both percapita and population herbivory rates should increase with increasing ambient temperature as both per-capita uptake and population growth rates will increase (Fig. 1b, e). By contrast, endothermic individuals, which maintain their body temperature across wide ranges of ambient temperature, may ingest more at cold temperatures to cover the increased metabolic cost of maintaining body temperature, resulting in decreased per-capita consumption rates at higher ambient temperatures (Fig. 1b). This prediction requires that lower temperatures actually increase energetic costs for the endotherm, which has been shown, e.g. for birds (Anderson \& Jetz 2005). Alternatively, per-capita consumption by endotherms may be independent of ambient temperature if ambient temperatures fall within the thermoneutral zone (i.e. the range of ambient temperatures over which body temperature can be maintained without additional costs) or if the additional costs for endothermy at low ambient temperatures are negligible (Humphries et al. 2005). For endothermic populations, we deduce that MTE predicts increased population consumption rates with increasing ambient temperature (Fig. 1e) due to lower per-capita energetic costs at higher ambient temperatures and/or higher gross growth efficiency at the population-level.

While MTE deals explicitly with temperature and body mass, the contents ( $\%$ of dry mass) and molar ratios of essential chemical elements often play important roles in mediating the efficiency of physiological and ecological processes in individuals, populations and communities (Sterner \& Elser 2002; Frost et al. 2006; Jeyasingh 2007). Ecological stoichiometry presents an independent body of theory seeking to explain the strength of trophic interactions based on principles of mass balance for multiple chemical elements (Sterner \& Elser 2002) combined with an understanding of patterns in physiological regulation of organismal elemental ratios in plants and animals (Frost et al. 2005a). Because herbivores have limited ability to store excess inorganic nutrients and show little variation in their body stoichiometry compared to plants (Elser et al. 2000a), feeding rates, growth rates and gross growth efficiencies of herbivores are determined - or at least constrained - by the balance of resource demands and the contents and ratios of resources in the food (Urabe \& Sterner 1996; Sterner et al. 1997). Indeed, large data compilations across terrestrial and aquatic ecosystems have shown that higher contents of essential elements, such as nitrogen $(\mathrm{N})$ and phosphorus $(\mathrm{P})$, in autotroph tissue are associated with higher rates of herbivory at population and community levels (Cebrian
1999; Cebrian \& Lartigue 2004). Other studies suggest that individual herbivores increase their intake rates when facing poor quality food (Cruz-Rivera \& Hay 2000). However, such compensation will result in lower growth efficiency and thus lower trophic efficiency when summed across all individuals in a population or community (Anderson et al. 2005; Frost et al. 2006).

The following predictions arise from considerations of ES: If individual herbivores compensate for decreasing autotroph nutritional quality (i.e. increasing mismatch between their own and autotroph nutrient ratios) to satisfy constant elemental demands, per-capita ingestion rates will increase with increasing mismatch (Fig. 1c). However, if herbivores have limited ability for compensatory feeding or actively avoid poor quality food (Frost \& Elser 2002), percapita consumption rates should be unchanged or reduced along a gradient of increasing nutritional mismatch (Fig. 1c). Since poor food quality can limit herbivore abundance and performance (Sterner \& Elser 2002), the potential increase in per-capita feeding may be insufficient to offset declining consumer abundance, leading to lower population-level herbivory with decreasing food quality (Hassett et al. 1997; Cebrian 1999; Cebrian \& Lartigue 2004) (Fig. 1f).

To evaluate the power of MTE and ES to explain major patterns in herbivory, we conducted a meta-analysis comprising $>350$ estimates of herbivory in freshwater, marine and terrestrial ecosystems. We analysed the rates of consumption by herbivores at the level of individuals and populations using herbivore body size, ambient temperature and stoichiometric mismatch between herbivore and autotroph as explanatory variables. We show that across ecosystems and a diverse taxonomic sampling of herbivores, metabolic and stoichiometric constraints each explain variation in consumption rates of autotroph biomass, although at distinct levels of organization and analysis.

\section{METHODS}

\section{Data}

Data on herbivory rates were obtained from published sources (see Supporting Information, Table S1). Search phrases used on literature databases were '(herbiv* OR graz*) and (stoichiometr* OR nutrient content OR C:N ratio OR C:P ratio)'. We included studies if they published rates of biomass removal by herbivores and information on autotroph nutritional quality. We expressed consumption of autotroph biomass as grams of carbon (C) removed per day per individual herbivore (per-capita herbivory rate) as well as per day per $\mathrm{m}^{2}$ (population herbivory rate). For aquatic studies, volume based estimates were transferred to 
surface based estimates based on the vertical dimension of the (experimental) system. To convert different units of reported autotroph biomass into carbon units, we assumed C to be $8 \%$ of the wet mass or $40 \%$ of the dry mass of autotroph material (Cebrian \& Lartigue 2004) and a C:chlorophyll ratio of 400 (Frost et al. 2005b). These conversion factors are rather coarse estimates with considerable variation around these means. However, in this analysis we deal with changes in herbivory rates over several orders of magnitude, so we assume that any deviation in carbon content estimation for a single species does not affect our major conclusions. Additionally, we obtained measures of autotroph nutritional quality in the form of nitrogen and phosphorus content (as \% of dry weight or as $\mathrm{P}$ - or $\mathrm{N}$-content relative to $\mathrm{C}$ ). Given the variability in autotroph nutrient content (Elser et al. 2000a), we only used herbivory estimates in which autotroph nutrient content was measured directly and reported within the study.

For herbivores, we characterized each species as endothermic or ectothermic and obtained measures of herbivore body size and $\mathrm{N}$ - and P-content from the original contribution, or - if missing - amended these with independent information on body size or nutrient content from the same or closely-related species. Although herbivore nutrient content is more constrained and less variable than in autotrophs (Elser et al. 2000a), we reran statistical analyses with subsets restricted to studies that directly measured and reported animal nutrient content. We report results from the more comprehensive dataset because our qualitative conclusions were unchanged (see Supporting Information, Table S2). We obtained estimates of ambient temperature during the study period from the original study or from a global air temperature database (available at http://climate.geog.udel.edu/ climate/).

A substantial fraction of studies provided information on either N- or P-content of the autotrophs, but not both. Therefore, we used an aggregate index of maximum mismatch in $\mathrm{N}$ - or P-content between consumer and autotroph to estimate the nutritional quality of the food relative to the consumer. If only $\mathrm{N}$ or $\mathrm{P}$ were given, we calculated the mismatch as $\ln$ (content herbivore/content autotroph). If both $\mathrm{N}$ and $\mathrm{P}$ were given, we calculated both mismatches and retained the larger index in order to indicate the maximum deviation of autotroph elemental composition from consumer demand. Mismatches in terms of $\mathrm{N}$ and $\mathrm{P}$ were highly correlated $(r=0.77, P<0.001)$. Use of the maximum difference was warranted because the element in shortest relative supply will determine the most acute elemental limitation of the herbivore (Frost et al. 2006). The maximum mismatch was always represented as a positive value, larger values therefore indicate greater nutritional mismatch.

\section{Statistical analyses}

We performed two general types of analyses in order to compare the relative importance of predictors of consumption rates specifically related to MTE and ES. First, we used general linear models (GLMs) to detect significant effects of ambient temperature, body size, thermoregulation (endo- or ectothermy) and stoichiometric mismatch on either percapita or population consumption rates. The best fitting models were selected using Akaike information criteria (AIC) (Johnson \& Omland 2004).

We then used structural equations models (SEMs) to ask whether a proposed set of causal pathways can reproduce the covariance structure among the variables in the original dataset. SEM is an extension of general linear modelling that uses maximum likelihood to solve for the set of regression coefficients among causal and response variables in a way that maximizes fit to an observed covariance matrix (Shipley 2000; Grace 2006). The resulting 'path' coefficients each represent the partial regression or correlation coefficient (depending on whether paths are standardized) after statistically holding all other pathways in the model constant. We began these modelling exercises by first constructing a saturated model in which ambient temperature, body size and stoichiometric mismatch were used as predictors of percapita and population-level rates of herbivory. We allowed for all three of the predictor variables to exhibit crosscorrelations (i.e. they were not assumed to be independent), and we allowed for the response variables to be correlated as well. We then set the least significant path (i.e. highest $P$-value) to zero, and examined whether removal of the path improved model fit, as judged by the AIC (where decreases in AIC $>2$ were deemed an improved fit, as suggested by Burnham \& Anderson (2002)). We continued to set all nonsignificant paths to zero (so long as doing so improved model fit) until we arrived at the most parsimonious model. We went through this same process, constructing SEMs similarly, for the entire data set, for ectotherms only, and for two ecologically similar groups - the zooplankton (primarily crustaceans) and macroinvertebrates (primarily gastropods and aquatic arthropods). Zooplankton and macroinvertebrates were the only two homogenous subsets of the data with sufficient observations to construct separate models. A separate model for endotherms was not possible given the limited number of observations.

To explicitly test the relative explanatory power of predictors related to MTE and ES for per-capita and population-level herbivory, we systematically deleted the causal pathways for predictors of body size and ambient temperature (MTE) or stoichiometric mismatch (ES) from the model. We then used AIC and log-likelihoods to assess whether loss of MTE or ES from the models significantly decreased the fit of the SEM to the data. 
The GLM and SEM analyses should be viewed as complementary to one another. The GLMs utilize the maximum amount of data available, as studies providing only per-capita or only population-level rates of herbivory could be included for separate analyses. These analyses comprised 354 estimates of per-capita rates of herbivory and 255 estimates of population-level rates. However, the GLM analyses are limited by the fact that they ignored the potential for co-linearity among the predictor variables of MTE (body size and ambient temperature) and ES (stoichiometric mismatch), as well as correlations between per-capita and population-level herbivory rates. On the other hand, the SEMs use only the subset of studies in which all relevant variables were measured simultaneously $(n=250)$. They do, however, specifically take account of the covariances among predictor and response variables.

\section{RESULTS}

\section{Across all groups of organisms}

Per-capita consumption rates strongly increased with larger body size of the herbivore over a range of 11 orders of magnitude in body size (Fig. 2a). Body size was the single most important factor for per-capita consumption in both GLM (Table 1) and SEM (Fig. 3a) analyses. A significant

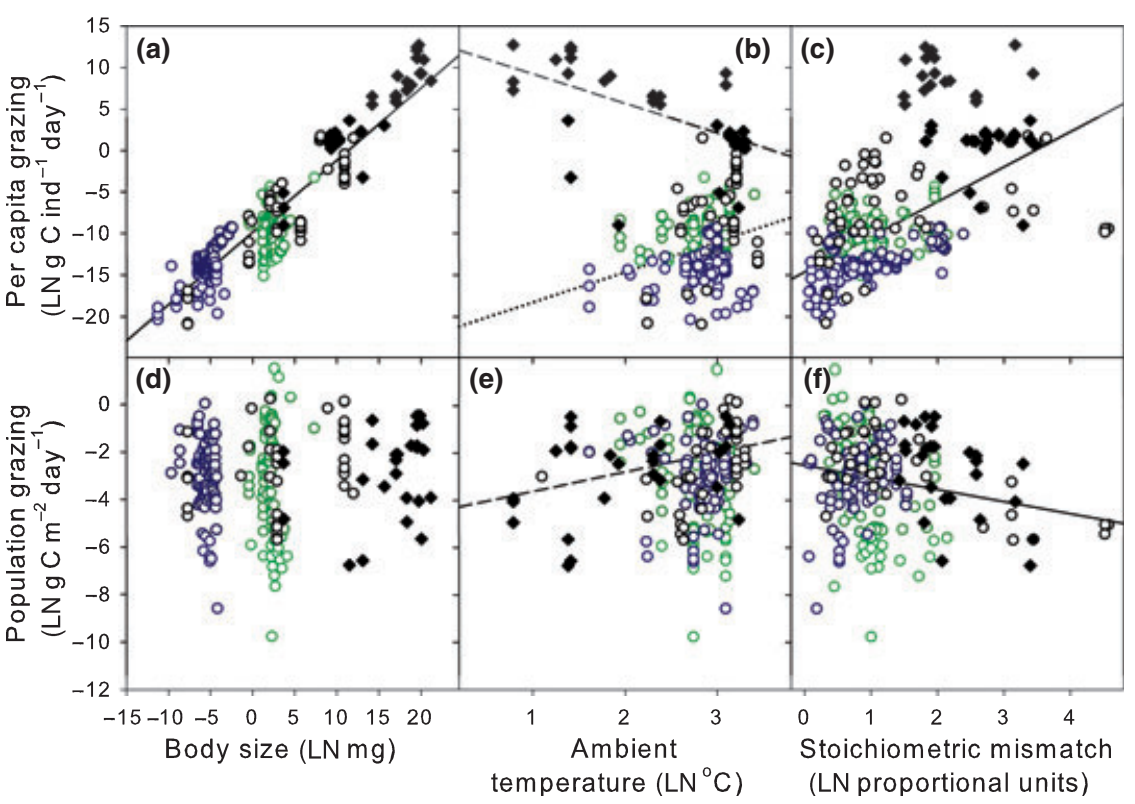

Figure 2 Per-capita $(\mathrm{a}-\mathrm{c})$ and populationlevel (d-f) rates of herbivory as related to the body size of the herbivore ( $a, d)$, the ambient temperature (b, e) and the stoichiometric mismatch between prey and consumers (c, f). Open symbols represent ectotherms, closed diamonds endotherms. Coloured points denote two consumer groups selected for restricted analyses (blue, zooplankton; green, macroinvertebrates).

Table 1 Analysis of per-capita and population rates of herbivory

\begin{tabular}{|c|c|c|c|c|c|}
\hline Response & Model (degrees of freedom) & $F$-ratio & $P$-level & $R^{2}$ & Estimate \\
\hline \multirow{5}{*}{$\begin{array}{l}\text { Per-capita } \\
\text { consumption }\end{array}$} & Full model $(5 ; 348)$ & 584.54 & $<0.0001$ & 0.8921 & \\
\hline & Herbivore size & 710.88 & $<0.0001$ & & $0.65(0.02)$ \\
\hline & Stoichiometric mismatch & 18.77 & $<0.0001$ & & $0.68(0.16)$ \\
\hline & Thermoregulation & 56.64 & $<0.0001$ & & $\mathrm{En}>\mathrm{Ec}$ \\
\hline & Temperature $\times$ thermoregulation & 13.28 & $<0.0001$ & & Ec: $1.82(0.42)$; En: -1.13 (0.39) \\
\hline \multirow{4}{*}{$\begin{array}{l}\text { Population } \\
\text { consumption }\end{array}$} & Full model $(3 ; 251)$ & 8.47 & $<0.0001$ & 0.0811 & \\
\hline & Stoichiometric mismatch & 20.76 & $<0.0001$ & & $-0.70(0.15)$ \\
\hline & Temperature & 2.7 & 0.1014 & & n.s. \\
\hline & Temperature $\times$ thermoregulation & 9.37 & 0.0024 & & Ec: 0.17 (0.25); En: $0.78(0.35)$ \\
\hline
\end{tabular}

En, endotherms; Ec, ectotherms.

For each response variable, the full model degrees of freedom, $F$-ratio, significance level $(P)$ and explained variance $\left(R^{2}\right)$ are given. For each factor remaining in the most parsimonious model, the $F$-ratio, significance level and an estimate of the slope of the effect ( \pm standard error) are given. 
(a) All data

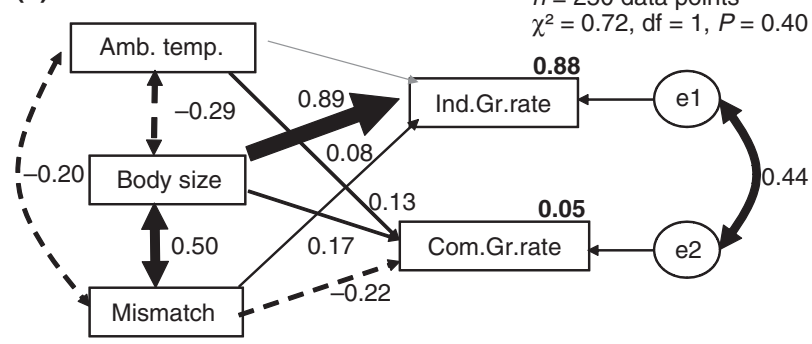

Zooplankton

(b)

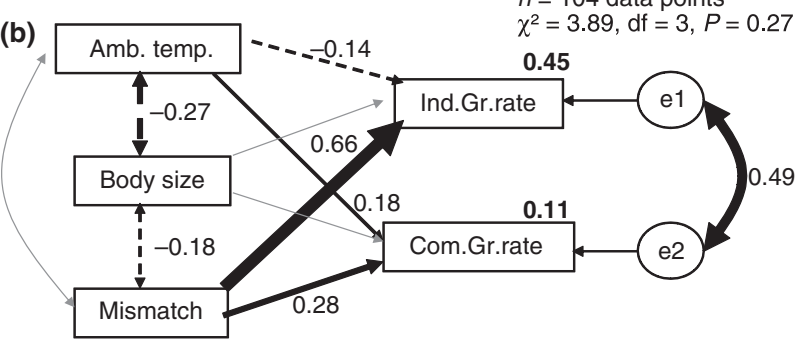

Macroinvertebrates

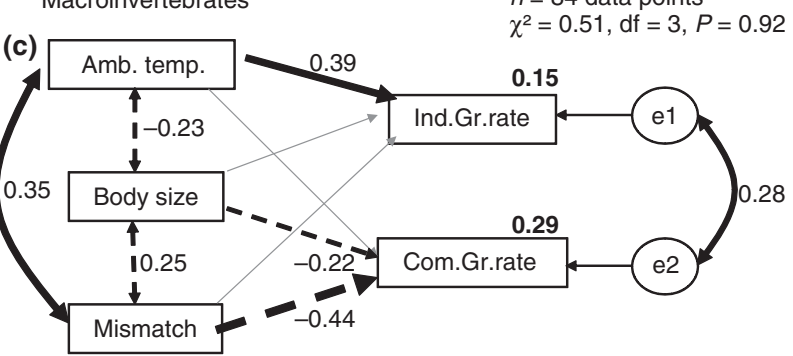

Figure 3 Structural equation models used to test the proposed impacts of ambient temperature, herbivore body size and stoichiometric mismatch on per-capita and population consumption rates. Standardized path coefficients by each arrow give the standard deviation change in the 'downstream' variable per standard deviation change in the 'upstream' variables. All coefficients represent significant relationships $(P<0.05)$ for the most parsimonious models, with dotted lines showing negative relationships and solid lines indicating positive relationships. Arrow thickness corresponds to the size of path coefficients. Bold numbers indicate explained variance for the respective consumption rate. (a) full data set. (b) zooplankton only. (c) macroinvertebrates.

temperature $\times$ thermoregulation interaction in the GLM (Table 1) demonstrated that consumption rates by individual endotherms declined at high ambient temperatures, but increased for individual ectotherms (Fig. 2b). As a consequence, there was no significant temperature effect on per-capita consumption rate in the full SEM (Fig. 3a). Restricting the SEM to ectotherms only resulted again in a positive relationship between consumption rate and ambient temperature (see Supporting Information, Figure S1). The stoichiometric mismatch had a small but significant positive effect on per-capita consumption rate (Fig. 2c) in both statistical analyses (Table 1, Fig. 3a). These variables together explained $88 \%$ (SEM) to $89 \%$ (GLM) of the variance in per-capita consumption rates.

At the population-level, only 5\% (SEM) to 8\% (GLM) of the variance in consumption rates could be explained by the predictors. Body size was not related to population consumption rate (Fig. 2d) and was not retained in the final GLM (Table 1). The SEM, however, showed a significant but weakly positive relationship between body mass and population consumption. With increasing ambient temperature, higher population-level consumption rates were observed (Figs 2e and 3a). The GLM indicated that this relationship was stronger for endothermic herbivores, whereas ectothermic herbivore communities showed a similar, albeit non-significant trend (Fig. 2e). Stoichiometric mismatch was the most important factor predicting population-level herbivory in both the GLM and SEM (Table 1, Fig. 3a), with increasing mismatch reducing population consumption rates (Fig. 2f).

\section{Within groups of organisms}

Restricting the analyses to ecologically similar groups strongly reduced the explanatory power of body size (Fig. 3b, c). Although the gradient in body mass for zooplankton or macroinvertebrates still included 2-3 orders of magnitude, body mass did not explain significant variation in consumption rate for either group (GLMs on these organism subsets were qualitatively identical, and are not shown here). At the population-level, consumption rates decreased weakly with body size for macroinvertebrates (Fig. 3c), but not for zooplankton (Fig. 3b). Temperature effects were weak and positive on average, but increasing ambient temperatures were strongly associated with increased per-capita consumption rates in macroinvertebrates. In contrast, stoichiometric mismatch between autotrophs and herbivores was much more important within restricted subsets of organisms. Increasing mismatch was associated with increased consumption rates by zooplankton at both the individual and population-levels of organization. Thus, individual zooplankters appear to increase their food intake in response to poor food quality, but - in contrast to the overall trend and the trend in all other subsets of organisms - this also increased the food intake at the level of the population. For macroinvertebrates, the per-capita stoichiometric effect was absent, whereas population-level consumption rates strongly declined with increasing mismatch. Overall, restricting the analysis to ecologically similar groups of organisms reduced the proportion of variation explained for per-capita consumption rates, but increased the proportion explained at the population-level. 


\section{The relative importance of ecological stoichiometry and metabolic theory of ecology}

Removal of either ES or MTE variables from the SEMs always significantly reduced the fit between the model and the observed covariance matrix (Table 2). Thus, variables related to metabolic or stoichiometric theories alone explained complementary subsets of the variation in herbivory in the full dataset, or in the datasets constrained to ectotherms, zooplankton, or macroinvertebrates (Table 2). However, the deletion of either MTE or ES had quite different effects on the explanatory power of the model. For the datasets including all organisms or ectotherms only, the deletion of MTE-related variables resulted in major reductions in the variance explained for per-capita consumption rates, whereas removing ES more strongly affected the model fit for population consumption rates. For zooplankton, the removal of ES-related variables reduced the variance explained for both per-capita and population consumption rates. For macroinvertebrates, MTE mattered more for individuals (mainly via ambient temperature, see Fig. 3c), but ES factored more strongly for populations.

\section{Macroecological patterns in the structural equations models}

The SEM revealed a strong negative correlation between body size and temperature in the overall data set (Fig. 3a), which was conserved for zooplankton and macroinvertebrate subsets (Fig. 3b, c). Thus, organisms tended to be smaller at higher temperatures, both across organism groups, but also within functional groups. Additionally, we found a strong positive correlation between body size and stoichiometric mismatch in the overall data set (Fig. 3a), which was much weaker within organism groups and even reversed for zooplankton alone (Fig. 3b). The correlations between ambient temperature and mismatch were less informative and ranged from negative (all data, Fig. 3a), zero (ectotherms, zooplankton, Fig. 3b), to positive (macroinvertebrates, Fig. 3c).

Table 2 A comparison of the results of different structural equation models

\begin{tabular}{|c|c|c|c|c|c|c|c|c|c|}
\hline Description & d.f. & $\chi^{2}$ & $P$ & AIC & $\Delta_{i}$ & $L\left(m_{i} \mid y\right)$ & $w_{i}$ & $R_{i}^{2}$ & $R_{c}^{2}$ \\
\hline \multicolumn{10}{|l|}{ All groups of organisms } \\
\hline Saturated model & & & & 40.0 & 1.3 & 0.5 & 0.3 & 0.88 & 0.05 \\
\hline Selected model & 1 & 0.7 & 0.4 & 38.7 & 0.0 & 1.0 & 0.7 & 0.88 & 0.05 \\
\hline Metabolic variables deleted & 4 & 477.8 & 0.0 & 509.8 & 471.0 & 0.0 & 0.0 & 0.28 & 0.03 \\
\hline Stochiometry deleted & 2 & 32.6 & 0.0 & 68.6 & 29.8 & 0.0 & 0.0 & 0.87 & 0.01 \\
\hline \multicolumn{10}{|l|}{ Ectotherms only } \\
\hline Saturated model & & & & 40.0 & 3.9 & 0.1 & 0.1 & 0.77 & 0.05 \\
\hline Selected model & 2 & 0.1 & 1.0 & 36.1 & 0.0 & 1.0 & 0.9 & 0.77 & 0.05 \\
\hline Metabolic variables deleted & 5 & 330.2 & 0.0 & 360.2 & 324.2 & 0.0 & 0.0 & 0.16 & 0.03 \\
\hline Stochiometry deleted & 3 & 38.1 & 0.0 & 72.1 & 36.1 & 0.0 & 0.0 & 0.76 & 0.01 \\
\hline \multicolumn{10}{|l|}{ Zooplankton only } \\
\hline Saturated model & & & & 40.0 & 2.1 & 0.3 & 0.3 & 0.47 & 0.11 \\
\hline Selected model & 3 & 3.9 & 0.3 & 37.9 & 0.0 & 1.0 & 0.7 & 0.45 & 0.11 \\
\hline Metabolic variables deleted & 5 & 17.4 & 0.0 & 47.4 & 9.5 & 0.0 & 0.0 & 0.45 & 0.07 \\
\hline Stochiometry deleted & 3 & 61.3 & 0.0 & 95.4 & 57.5 & 0.0 & 0.0 & 0.06 & 0.05 \\
\hline \multicolumn{10}{|l|}{ Macroinvertebrates only } \\
\hline Saturated model & & & & 40.0 & 5.5 & 0.1 & 0.1 & 0.15 & 0.31 \\
\hline Selected model & 3 & 0.5 & 0.9 & 34.5 & 0.0 & 1.0 & 0.9 & 0.15 & 0.29 \\
\hline Metabolic variables deleted & 4 & 18.9 & 0.0 & 50.9 & 16.4 & 0.0 & 0.0 & 0.01 & 0.26 \\
\hline Stochiometry deleted & 2 & 16.0 & 0.0 & 52.0 & 17.5 & 0.0 & 0.0 & 0.15 & 0.16 \\
\hline
\end{tabular}

d.f., degrees of freedom; AIC, Akaike information criteria; $\Delta_{i}$, AIC score; $\mathrm{L}\left(m_{i} \mid y\right)$, likelihood, $w_{i}$, Akaike weight.

For each set of organisms, we compared a saturated model with all possible links, the selected model with all non-significant interactions removed (see Fig. 3), as well as two scenarios where the metabolic variables (body size and temperature) or stoichiometric mismatch were removed from the model entirely.

The log-likelihood and Akaike weights (Burnham \& Anderson (2002) were used to compare the relative fits among these alternative models. In all four cases, the model chosen as having the best fit to the observed covariance matrix included both metabolic and stoichiometric variables.

The last two columns give the explained variances for the two dependent variables - per-capita $\left(R^{2} \imath\right)$ and population-level $\left(R^{2} c\right)$ consumption rates. 


\section{DISCUSSION}

Our analyses suggest that predictions derived from both MTE and ES explain significant amounts of the variation in herbivory across ecosystems, but that the relative importance of these predictors strongly depends on the range of organisms included and on whether per-capita or population consumption is addressed. The removal of either metabolic or stoichiometric predictor variables had very different consequences for the variance explained at different levels of organization, but for all subsets of data MTE and ES provided complementary information on rates of herbivory, reflected by both statistical analyses (SEM and GLM).

Body size was the most important factor predicting percapita consumption rates when analysed across large gradients of consumer body size. Over our $10^{11}$-fold gradient in herbivore size ranging from small zooplankton $(\sim 1 \mu \mathrm{g})$ to large mammalian herbivores $(>500 \mathrm{~kg})$, larger species consistently (and unsurprisingly) consumed more biomass per-capita. This simple relationship accounted for a large proportion of variance in per-capita consumption rates $(>80 \%)$. However, within restricted functional subsets, body size had virtually no explanatory relevance for percapita rates of herbivory, despite the fact that these constrained groups still encompassed 2-3 orders of magnitude differences in body size. Strong allometric relationships between consumption rate and body size have been found on more restricted body mass gradients (Jeyasingh 2007). However, body size typically explains less variance in important ecological rates (population growth, mortality) when reducing the body size gradient to ranges often observed within ecological communities (Tilman et al. 2004). Thus, despite the overriding importance of body size for per-capita rates of herbivory across all organisms in the full data set, size had little predictive power when considering body size ranges spanning only a few orders of magnitude. In accordance with predictions from MTE and the energyequivalence rule (Damuth 1981; Allen et al. 2002; Ernest et al. 2003), body size had little explanatory power for population-level consumption in any data subset. This is noteworthy since consumption at the population or community level often is the organizational scale of interest for predicting changes in the functioning of ecosystems (Cebrian 1999; Gruner et al. 2008).

Metabolic theory of ecology not only allows testing qualitative predictions, but also mechanistically predicts the slope of the relationship between consumption rates and either body size or temperature. In our analysis, we did not attempt a formal quantitative test of these theoretically derived slopes. Because the rates of herbivory included in our database were derived in various ways depending on the empirical study and the conversion factors employed were coarse (see Methods), these data would not allow a valid test of these quantitative predictions. Moreover, we did not include autotroph size into our body size considerations, as there was no clear-cut way to estimate plant body size from the primary studies. In a very large data comparison, Brose et al. (2006) showed that body size ratios of consumers to prey varied dramatically between ecosystem types as well as between endotherm and ectotherm consumers. Based on the model by Yodzis \& Innes (1992), Shurin \& Seabloom (2005) predicted higher trophic control of herbivores on their plant prey at higher body size ratios. The body size ratio will have further important consequences for this interaction, e.g. the ability of consumers to select prey items (Hillebrand 2003).

Ambient temperature was consistently retained as a significant predictor for herbivory rates in most GLMs and SEMs, although it explained relatively small fractions of the total variance. For per-capita consumption rates, the differing metabolic costs for endothermic and ectothermic strategies clearly played a role. Increasing ambient temperature enhanced the ability of individual ectotherms to ingest food, whereas endothermic organisms reduced consumption rates at warmer ambient temperatures, consistent with our predictions. The most plausible explanation is that, at colder ambient temperatures, individual endothermic herbivores need more energy to maintain endothermy (Porter \& Gates 1969; Porter et al. 2000). A recent comparison of bird energetic expenditure showed that lower ambient temperatures lead to higher mass-corrected metabolic rates, which support the hypotheses that cold ambient temperatures increase energy demand in endotherms (Anderson \& Jetz 2005). At the population-level, increasing ambient temperatures were associated with increased rates of herbivory throughout our data set.

The positive relationship between herbivory rates and the stoichiometric mismatch between consumers and producers indicate that individual grazers increase their intake in response to lower food quality. This capacity has been observed for a variety of herbivore groups (Williams et al. 1994; Hughes \& Bazzaz 1997; Cruz-Rivera \& Hay 2000). However, population-level consumption is the product of per-capita intake and herbivore abundance. Lower food quality often reduces herbivore growth efficiency and population growth rate (Williams et al. 1994; Boersma \& Kreutzer 2002; Frost \& Elser 2002), causing the decline in population-level consumption with increasing stoichiometric mismatch.

This result suggests that variation in plant chemical composition places major constraints on energy transfer at the plant-herbivore interface. The effect of stoichiometry was weak but significant when considering the entire size range of herbivores from microcrustaceans to mammals (Fig. 1). While size and ambient temperature are clearly important determinants of individual feeding rates, our data 
suggest that population ingestion rate is unrelated to size. Instead, stoichiometric mismatch emerges as a more important factor within groups of organisms with similar sizes and ecological roles (e.g. zooplankton or macroinvertebrates).

Based on our analyses, we highlight some contrasts in the association of stoichiometric mismatch and consumption rate between aquatic organism groups. In contrast to zooplankton (below), there was no evidence that per-capita consumption rates of macroinvertebrates increased as a function of food quality. The present dataset does not incorporate information that would allow us to explicitly test potential causes of this difference, but several fundamental differences may contribute to this contrast. Macroinvertebrates feed on a very abundant food (high biomass) of low nutritional quality, as periphyton constitutes high detritus content and high C:nutrient ratios (Kahlert et al. 2002; Frost et al. 2005b). In contrast, zooplankton feed on suspended particulate matter dominated by phytoplankton (seston) that generally is higher in nutrient content than benthic biofilms. Thus, macroinvertebrates may already feed at saturated ingestion rates irrespective of food quality and have less flexibility to increase individual uptake. Moreover, a majority of the zooplankton data were derived from controlled predator-free laboratory experiments, whereas our data set contains numerous field experiments for macroinvertebrates. In the field, higher herbivore activity can result in higher predation risk, and predator presence may constrain herbivory (Boström \& Mattila 1999; Diehl et al. 2000; Turner et al. 2000; Schmitz 2008). Organisms that adjust their foraging behaviour to minimize foraging time (and the associated risks of predation) may not increase grazing rates as a response to lowered food quality (Schoener 1971; Frost \& Elser 2002; Schmitz 2008).

Zooplankton were the only group showing a positive relationship between population-level consumption rate and increasing stoichiometric mismatch. Again, we lack clear indications of what has caused this reversed relationship in our dataset. Given the fact that various field studies indicate lower zooplankton biomass at poor seston quality (Hessen 1992; Urabe et al. 2002), we speculate that this relationship is a consequence of the high number of short-term lab experiments under highly controlled conditions used in this category. Over the short time span used in most of these lab studies, food quality constraints on reproduction and thus abundance presumably did not play a role.

Overall, our models explained less variation in consumption rates at the population-level than at the individual level. The collapse of the strong body size signal present in the individual grazing rates suggests a lower ability to predict population grazing rates, which is in line with predictions from energy-equivalence (Damuth 1981). This implies an important role for population size, which also scales to body size (Belgrano et al. 2002). Many additional factors may contribute to variation in herbivory at the population-level. Among these, the presence of predators can reduce population-level herbivory rates by altering herbivore density or behaviour (Trussell et al. 2002; Schmitz et al. 2004; Preisser et al. 2005). Shifts in autotroph community composition and palatability due to herbivory and nutrient supply (Bazzaz et al. 1987; Steiner 2003; Strengbom et al. 2003; Howe et al. 2006; Hillebrand et al. 2007; Gruner et al. 2008) may also alter the relationship between simple predictor variables and population-level herbivory. Moreover, temporal (seasonal) and spatial patchiness of autotroph availability may have a much larger role at the level of herbivore populations than for individual herbivores (Norrdahl et al. 2002; Hambäck et al. 2004). Thus, herbivore populations may not be able to track shifting resource abundance due to intrinsic dynamics or extrinsic forces, introducing other sources of variation into the population grazing rates. It should be noted that the ability of the SEMs to explain population-level herbivory increased when the analysis was confined to restricted community types, which might eliminate some of the variance between studies described above.

Our findings indicate that MTE and ES address different aspects of the autotroph-herbivore interaction and that each offers predictive power at different levels of organization. Both bodies of theory address problems across different scales of organization from cells (or even molecules) to ecosystems (Elser et al. 2000b; Brown et al. 2004) and they have been jointly used to explain micro- (Jeyasingh 2007) and macroecological (Kerkhoff et al. 2005) observations. In our analysis, the explanatory power of predictions based on these two theories strongly depended on the scale of biological organization addressed. Size was clearly the dominant factor determining the feeding rate of individuals when considering a range of herbivores from protists to ungulates. Populations of large and small organisms consume carbon at roughly equivalent rates, which indicates that increased per-capita grazing is balanced, e.g. by declining population density (c.f. the energetic equivalence rule, Damuth 1981). In scaling individual performance to ecosystem trophic structure, stoichiometric imbalance appears to be an important factor limiting trophic efficiency and rates of herbivory. Predictions based on metabolic theory were best suited for understanding variation between organisms that differ greatly in size, while stoichiometric theory was most appropriate for explaining differences between organisms within ecosystems.

Significant cross-correlations among the explanatory variables in the SEM point to important macroecological patterns. The strong negative correlation between body size and temperature corresponds to the Bergmann's Rule for endotherms (Meehan et al. 2004), which was recently also tested for ectotherms (Belk \& Houston 2002; Angilletta \& 
Dunham 2003). In all datasets except for the zooplankton subset there was a positive correlation between herbivore size and stoichiometric mismatch. For all herbivores and the ectothermic subset, the largest herbivores were vertebrates, which have an overall higher body nutrient content (Sterner \& Elser 2002) and drove this covariance relationship. Moreover, larger herbivores tended to be terrestrial; in this habitat, overall lower nutrient content of the autotrophs likely contributed to larger stoichiometric mismatch (Cebrian 1999; Shurin et al. 2006). For invertebrates, previous studies showed that smaller organisms, which usually have higher growth rates, also tend to have larger P-content (Elser et al. 2000b; Liess \& Hillebrand 2005). In our dataset, we found this pattern only for zooplankton, but not macroinvertebrates.

Our results involve exploratory empirical analyses of herbivory across different scales of organization. However, a strict mechanistic test of predictions from these two bodies of theory would need to involve controlled measurement or manipulation of consumer body size, temperature and stoichiometric composition. Some preliminary analyses of stoichiometry and body size (Jeyasingh 2007) as well as stoichiometry and temperature (Woods et al. 2003) have informed our understanding of the synergism between these bodies of theory. Our analysis is a first step towards a synthesis given the inherent variability of the data sources used here. Environmental parameters relevant to both ES and MTE are changing on a global scale due to human alterations of biogeochemical cycles and temperature profiles. Therefore, the interaction between metabolic and stoichiometric constraints and the interdependency of constraints at macro- and microscales should be the focus of more refined future studies.

\section{ACKNOWLEDGEMENTS}

We thank P.D. Jeyasingh, F. Darchambeau and D.O. Hessen for making unpublished data available and/or sending additional information on published papers. The manuscript was improved by comments from Elizabeth Wolkovich, Paul Frost and Ulrich Brose and profited further from comments from David Storch, Drew Kerkhoff and two anonymous reviewers. Funding was provided by the National Centre for Ecological Analysis and Synthesis, a Centre funded by NSF (grant no. DEB-0072909), the University of California and UC Santa Barbara. HH was additionally funded by the German Science foundation (DFG grant Hi838/3-2).

\section{REFERENCES}

Allen, A.P., Brown, J.H. \& Gillooly, J.F. (2002). Global biodiversity, biochemical kinetics, and the energetic-equivalence rule. Science, 297, 1545-1548.
Anderson, K.J. \& Jetz, W. (2005). The broad-scale ecology of energy expenditure of endotherms. Ecol. Lett., 8, 310-318.

Anderson, T.R., Hessen, D.O., Elser, J.J. \& Urabe, J. (2005). Metabolic stoichiometry and the fate of excess carbon and nutrients in consumers. Am. Nat., 165, 1-15.

Angilletta, M.J. \& Dunham, A.E. (2003). The temperature-size rule in ectotherms: simple evolutionary explanations may not be general. Am. Nat., 162, 332-342.

Bazzaz, F.A., Chiariello, N.R., Coley, P.D. \& Pitelka, L.F. (1987). Allocating resources to reproduction and defense. Bioscience, 37, $58-65$.

Belgrano, A., Allen, A.P., Enquist, B.J. \& Gillooly, J.F. (2002). Allometric scaling of maximum population density: a common rule for marine phytoplankton and terrestrial plants. Ecol. Lett., 5, 611-613.

Belk, M.C. \& Houston, D.D. (2002). Bergmann's rule in ectotherms: a test using freshwater fishes. Am. Nat., 160, 803808.

Bishop, J.A. \& Armbruster, W.S. (1999). Thermoregulatory abilities of Alaskan bees: effects of size, phylogeny and ecology. Funct. Ecol., 13, 711-724.

Boersma, M. \& Kreutzer, C. (2002). Life at the edge: is food quality really of minor importance at low quantities? Ecology, 83, 25522561.

Borer, E.T., Halpern, B.S. \& Seabloom, E.W. (2006). Asymmetry in community regulation: effects of predators and productivity. Ecology, 87, 2813-2820.

Boström, C. \& Mattila, J. (1999). The relative importance of food and shelter for seagrass-associated invertebrates: a latitudinal comparison of habitat choice by isopod grazers. Oecologia, 120, 162-170.

Brett, M.T. \& Goldberg, D.E. (1996). A meta-analysis of the freshwater trophic cascade. Proc. Natl. Acad. Sci. USA, 93, 77237726.

Brose, U., Jonsson, T., Berlow, E.L., Warren, P., Banasek-Richter, C., Bersier, L.F. et al. (2006). Consumer-resource body-size relationships in natural food webs. Ecology, 87, 2411-2417.

Brown, J.H., Gillooly, J.F., Allen, A.P., Savage, V.M. \& West, G.B. (2004). Toward a metabolic theory of ecology. Ecology, 85, 17711789.

Bryant, S.R., Thomas, C.D. \& Bale, J.S. (2002). The influence of thermal ecology on the distribution of three nymphalid butterflies. J. Appl. Ecol., 39, 43-55.

Burnham, K.P. \& Anderson, D.R. (2002). Model Selection and MultiModel Inference, 2nd edn. Springer, New York.

Cebrian, J. (1999). Patterns in the fate of poduction in plant communities. Am. Nat., 154, 449-468.

Cebrian, J. \& Lartigue, J. (2004). Patterns of herbivory and decomposition in aquatic and terrestrial ecosystems. Ecol. Monogr., 74, 237-259.

Cruz-Rivera, E. \& Hay, M.E. (2000). Can quantity replace quality? Food choice, compensatory feeding, and fitness of marine mesograzers. Ecology, 81, 201-219.

Damuth, J. (1981). Population-density and body size in mammals. Nature, 290, 699-700.

Damuth, J. (2007). Macroevolutionary explanation, a for Equivalence, energy in the scaling of body size and population density. Am. Nat., 169, 621-631.

Diehl, S., Cooper, S.D., Kratz, K.W., Nisbet, R.M., Roll, S.K., Wiseman, S.W. et al. (2000). Effects of multiple, predator-in- 
duced behaviors on short-term producer-grazer dynamics in open systems. Am. Nat., 156, 293-313.

Economo, E.P., Kerkhoff, A.J. \& Enquist, B.J. (2005). Allometric growth, life-history invariants and population energetics. Ecol. Lett., 8, 353-360.

Elser, J.J., Fagan, W.F., Denno, R.F., Dobberfuhl, D.R., Folarin, A., Huberty, A. et al. (2000a). Nutritional constraints in terrestrial and freshwater food webs. Nature, 408, 578-580.

Elser, J.J., Sterner, R.W., Gorokhova, E., Fagan, W.F., Markow, T.A., Cotner, J.B. et al. (2000b). Biological stoichiometry from genes to ecosystems. Ecol. Lett., 3, 540-550.

Emmerson, M.C. \& Raffaelli, D. (2004). Predator-prey body size, interaction strength and the stability of a real food web. J. Anim. Ecol., 73, 399-409.

Ernest, S.K.M., Enquist, B.J., Brown, J.H., Charnov, E.L., Gillooly, J.E., Savage, V. et al. (2003). Thermodynamic and metabolic effects on the scaling of production and population energy use. Ecol. Lett., 6, 990-995.

Frost, P.C. \& Elser, J.J. (2002). Growth responses of littoral mayflies to the phosphorus content of their food. Ecol. Lett., 5, 232-240.

Frost, P.C., Evans- White, M.A., Finkel, Z.V., Jensen, T.C. \& Matzek, V. (2005a). Are you what you eat? Physiological constraints on organismal stoichiometry in an elementally imbalanced world. Oikos, 109, 18-28.

Frost, P.C., Hillebrand, H. \& Kahlert, M. (2005b). Low algal carbon content and its effect on the C : P stoichiometry of periphyton. Freshw. Biol., 50, 1800-1807.

Frost, P.C., Benstead, J.P., Cross, W.F., Hillebrand, H., Larson, J.H., Xenopoulos, M.A. et al. (2006). Threshold elemental ratios of carbon and phosphorus in aquatic consumers. Ecol. Lett., 9, 774-779.

Grace, J.B. (2006). Structural Equation Modeling and Natural Systems. Cambridge University Press, Cambridge.

Gruner, D.S., Smith, J.E., Seabloom, E.W., Sandin, S.A., Ngai, J.T., Hillebrand, H. et al. (2008). A cross-system synthesis of consumer and nutrient resource control on producer biomass. Ecol. Lett., 11, 740-755.

Hambäck, P.A., Oksanen, L., Ekerholm, P., Lindgren, A., Oksanen, T. \& Schneider, M. (2004). Predators indirectly protect tundra plants by reducing herbivore abundance. Oikos, 106, 85-92.

Hassett, R.P., Cardinale, B., Stabler, L.B. \& Elser, J.J. (1997). Ecological stoichometry of $\mathrm{N}$ and $\mathrm{P}$ in pelagic ecosystems: comparison of lakes and oceans with emphasis on the zooplankton-phytoplankton interaction. Limnol. Oceanogr., 42, 648662.

Hessen, D.O. (1992). Nutrient element limitation of zooplankton production. Am. Nat., 140, 799-814.

Hillebrand, H. (2003). Opposing effects of grazing and nutrients on diversity. Oikos, 100, 592-600.

Hillebrand, H., Gruner, D.S., Borer, E.T., Bracken, M.E.S., Cleland, E.E., Elser, J.J. et al. (2007). Consumer versus resource control of producer diversity depends on ecosystem type and producer community structure. Proc. Natl. Acad. Sci. USA, 104, 10904-10909.

Howe, H.F., Zorn-Arnold, B., Sullivan, A. \& Brown, J.S. (2006). Massive and distinctive effects of meadow voles on grassland vegetation. Ecology, 87, 3007-3013.

Hughes, L. \& Bazzaz, F.A. (1997). Effect of elevated $\mathrm{CO}_{2}$ in interactions between the western flowerthrips Frankliniella occidentalis (Thysanoptera: Thripidae) and the common milkweed, Asclepias syriaca. Oecologia, 109, 286-290.

Humphries, M.M., Boutin, S., Thomas, D.W., Ryan, J.D., Selman, C., McAdam, A.G. et al. (2005). Expenditure freeze: the metabolic response of small mammals to cold environments. Ecol. Lett., 8, 1326-1333.

Jeyasingh, P.D. (2007). Plasticity in metabolic allometry: the role of dietary stoichiometry. Ecol. Lett., 10, 282-289.

Johnson, J.B. \& Omland, K.S. (2004). Model selection in ecology and evolution. Trends Ecol. Evol., 19, 101-108.

Kahlert, M., Hasselrot, A.T., Hillebrand, H. \& Pettersson, K. (2002). Spatial \& temporal variation in the biomass and nutrient status of epilithic algae in Lake Erken, Sweden. Freshw. Biol., 47, $1191-1215$.

Kerkhoff, A.J., Enquist, B.J., Elser, J.J. \& Fagan, W.F. (2005). Plant allometry, stoichiometry \& the temperature-dependence of primary productivity. Glob. Ecol. Biogeogr., 14, 585-598.

Liess, A. \& Hillebrand, H. (2005). Stoichiometric variation in C: N, $\mathrm{C}: \mathrm{P}$, and $\mathrm{N}: \mathrm{P}$ ratios of littoral benthic invertebrates. J. North. Am. Benthol. Soc., 24, 256-269.

Loeuille, N. \& Loreau, M. (2006). Evolution of body size in food webs: does the energetic equivalence rule hold? Ecol. Lett., 9, 171-178.

McNaughton, S.J., Ruess, R.W. \& Seagle, S.W. (1988). Large mammals and process dynamics in African ecosystems. Bioscience, 38, 794-800.

McQueen, D.J., Johannes, M.R.S., Post, J.R., Stewart, T.J. \& Lean, D.R. (1989). Bottom-up and top-down impacts on freshwater pelagic community structure. Ecol. Monogr., 59, 289-309.

Meehan, T.D., Jetz, W. \& Brown, J.H. (2004). Energetic determinants of abundance in winter landbird communities. Ecol. Lett., 7, 532-537.

Nee, S., Read, A.F., Greenwood, J.J.D. \& Harvey, P.H. (1991). The relationship between abundance and body size in british birds. Nature, 351, 312-313.

Norrdahl, K., Klemola, T., Korpimaki, E. \& Koivula, M. (2002). Strong seasonality may attenuate trophic cascades: vertebrate predator exclusion in boreal grassland. Oikos, 99, 419-430.

Porter, W.P. \& Gates, D.M. (1969). Thermodynamic equilibria of animals with environment. Ecol. Monogr., 39, 227-244.

Porter, W.P., Budaraju, S., Stewart, W.E. \& Ramankutty, N. (2000). Calculating climate effects on birds and mammals: impacts on biodiversity, conservation, population parameters, and globalcommunity structure. Am. Zool., 40, 597-630.

Preisser, E.L., Bolnick, D.I. \& Benard, M.F. (2005). Scared to death? The effects of intimidation and consumption in predatorprey interactions. Ecology, 86, 501-509.

Schmitz, O.J. (2008). Herbivory from individuals to ecosystems. Ann. Rev. Ecol. Evol. Syst., 39, 133-152.

Schmitz, O.J., Krivan, V. \& Ovadia, O. (2004). Trophic cascades: the primacy of trait-mediated indirect interactions. Ecol. Lett., 7, 153-163.

Schoener, T.W. (1971). Theory of feeding strategies. Annu. Rev. Ecol. Syst., 2, 369-404.

Shipley, B. (2000). Cause and Correlation in Biology: A User's Guide to Path Analysis, Structural Equations, and Causal Inference. Cambridge University Press, Cambridge.

Shurin, J.B. \& Seabloom, E.W. (2005). The strength of trophic cascades across ecosystems: predictions from allometry and energetics. J. Anim. Ecol., 74, 1029-1038. 
Shurin, J.B., Gruner, D.S. \& Hillebrand, H. (2006). All wet or dried up? Real differences between aquatic and terrestrial food webs. Proc. R. Soc. B Biol. Sci., 273, 1-9.

Steiner, C.F. (2003). Keystone predator effects and grazer control of planktonic primary production. Oikos, 101, 569-577.

Sterner, R.W. \& Elser, J.J. (2002). Ecological Stoichiometry. Princeton University Press, Princeton.

Sterner, R.W., Elser, J.J., Fee, E.J., Guildford, S.J. \& Chrzanowski, T.H. (1997). The light:nutrient ratio in lakes: the balance of energy and materials affects ecosystem structure and process. Am. Nat., 150, 663-684.

Strengbom, J., Olofsson, J., Witzell, J. \& Dahlgren, J. (2003). Effects of repeated damage and fertilization on palatability of Vaccinium myrtillus to grey sided voles, Clethrionomys rufocanus. Oikos, 103, 133-141.

Tilman, D., Hillerislambers, J., Harpole, S., Dybzinski, R., Fargione, J., Clark, C. et al. (2004). Does metabolic theory apply to community ecology? It's a matter of scale. Ecology, 85, 1797-1799.

Trussell, G.C., Ewanchuk, P.J. \& Bertness, M.D. (2002). Field evidence of trait-mediated indirect interactions in a rocky intertidal food web. Ecol. Lett., 5, 241-245.

Turner, A.M., Bernot, R.J. \& Boes, C.M. (2000). Chemical cues modify species interactions: the ecological consequences of predator avoidance by freshwater snails. Oikos, 88, 148-158.

Urabe, J. \& Sterner, R.W. (1996). Regulation of herbivore growth by the balance of light and nutrients. Proc. Natl. Acad. Sci. USA, 93, 8465-8469.

Urabe, J., Kyle, M., Makino, W., Yoshida, T., Andersen, T. \& Elser, J.J. (2002). Reduced light increases herbivore production due to stoichiometric effects of light/nutrient balance. Ecology, 83, 619627.

Vasseur, D.A. \& McCann, K.S. (2005). A mechanistic approach for modeling temperature-dependent consumer-resource dynamics. Am. Nat., 166, 184-198.

West, G.B., Brown, J.H. \& Enquist, B.J. (1997). A general model for the origin of allometric scaling laws in biology. Science, 276, 122-126.

White, E.P., Ernest, S.K.M., Kerkhoff, A.J. \& Enquist, B.J. (2007). Relationships between body size and abundance in ecology. Trends Ecol. Evol., 22, 323-330.
Williams, R.S., Lincoln, D.E. \& Thomas, R.B. (1994). Loblolly pine grown under elevated $\mathrm{CO}_{2}$ affects early instar pine sawfly performance. Oecologia, 98, 64-71.

Woods, H.A., Makino, W., Cotner, J.B., Hobbie, S.E., Harrison, J.F., Acharya, K. et al. (2003). Temperature and the chemical composition of poikilothermic organisms. Funct. Ecol., 17, 237-245.

Woodward, G., Ebenman, B., Emmerson, M., Montoya, J.P., Olesen, J.M., Valido, A. et al. (2005). Body size in ecological networks. Trends Ecol. Evol., 20, 402-409.

Yodzis, P. \& Innes, S. (1992). Body size and consumer-resource dynamics. Am. Nat., 139, 1151-1175.

\section{SUPPORTING INFORMATION}

Additional Supporting Information may be found in the online version of this article:

Figure S1 Structural equation model on ectothermic herbivores.

Table S1 List of data sets and estimates used for the present analyses.

Table S2 Comparison of the analysis of per-capita and population rates of herbivory for all ectotherms and for those ectotherms, for which estimates of body nutrient content was available directly.

Please note: Wiley-Blackwell are not responsible for the content or functionality of any supporting materials supplied by the authors. Any queries (other than missing material) should be directed to the corresponding author for the article.

Editor, David Storch

Manuscript received 23 January 2009

Manuscript accepted 23 February 2009 